\title{
Asociacionismo, ciudadanía y bienestar social ${ }^{1}$
}

\author{
Antonio Ariño Villarroya \\ Universitat de València
}

\section{Resumen}

Durante las dos últimas décadas del siglo XX, se ha producido un giro histórico en el asociacionismo español, que se plasma tanto en la creación de asociaciones y en la participación asociativa, como en la institucionalización (leyes del voluntariado, de asociaciones, etc.) y en el interés académico que suscita el fenómeno. Tres interpretaciones se han dado del mismo: una utópica, que lo considera como expresión de una radicalización participativa; otra crítica, que ve en el mismo un subterfugio para diluir la privatización del Estado de bienestar, y una integrada, que habla en términos de la aparición de un tercer sector junto al mercado y el Estado. Cada una de ellas es sugerente, pero insuficiente. Tienen una validez parcial. Aquí se efectúa una revisión de las mismas, mediante una propuesta de estudio del fenómeno asociativo desde una perspectiva omniabarcante, mediante un análisis de su heterogeneidad interna y mediante la indagación cualitativa sobre la existencia o no de proyecto y significado político en el seno de las asociaciones.

Palabras clave: asociacionismo, ciudadanía, tercer sector, bienestar.

\section{Abstract. Associationism, citizenship and social welfare}

The last two decades of the XX century have produced a historical change in what concerns Spanish associationism, which not only takes place in the creation of associations and in associative participation but also in the institutionalization (volunteering and association laws, etc.) and academic interest which the phenomenon provokes. This change has been interpreted in three different ways: a utopian one which considers it as an expression of participatory radicalization; a critical one which believes that the change is a subterfuge to dilute the privatization of the Welfare State, and an integrated one which speaks in terms of the appearance of a third sector together with the market and the State. Each of them is evocative but clearly insufficient. They all have partial validity. We here revise these interpretations, by means of a study proposal of the associative phenomenon from an omniencompassing perspective, by means of an analysis of its internal heterogeneity and by means of the qualitative inquiry on the existence or the non-existence of the project and political meaning within associations.

Key words: associationism, citizenship, third sector, welfare.

1. Una primera versión de este texto fue presentada a debate en las Jornadas de Sociología Política, organizadas por el Comité de Investigación Social Política de la Federación Española de Sociología, en Madrid, durante los días 26 y 27 de septiembre de 2002. Agradezco todos los comentarios y sugerencias recibidas. 


\section{Sumario}

1. Un giro histórico en el asociacionismo

2. Multiplicidad de factores generadores de asociatividad y predominio de la sociabilidad

3. La heterogeneidad en el seno del altruismo
4. Apatía política y participación cívica

5. La renovación de lo social

Anexo. Conglomerados finales de las ONG valencianas

Bibliografía

\section{Un giro histórico en el asociacionismo}

El mundo moderno tiene un cimiento asociativo y, a su vez, las estructuras políticas y sociales de la modernidad propician el desarrollo de una pluralidad de asociaciones. La cooperación voluntaria entre personas que se organizan formalmente para lograr determinados intereses comunes constituye, a un tiempo, un espacio privilegiado para ensayar formas modernas de sociedad y un resultado de los procesos que operan en éstas.

En el siglo XVIII y principios del XIX, tanto en Europa como en América, tal y como mostró en su día Alexis de Tocqueville y más tarde Maurice Agulhon, hubo una proliferación de formas de agrupación (sociedades de amigos del país, salones, círculos, academias, cafés, sociedades literarias, logias de francmasones...) que, consideradas en conjunto, desde la perspectiva de los largos procesos, conformaron un movimiento sociocultural en el que se alumbraban nuevos valores, se experimentaban espacios y formas nuevas de producir sociedad, sobre la base de la pertenencia voluntaria (Im Hof, 1995). Este movimiento, que se prolongó después y se ramificó mediante los partidos políticos, los sindicatos y una prolífica heterogeneidad de tipos asociativos, también efectuó una contribución sustantiva a la transición desde las estructuras feudales regidas por rangos y estatus, a la sociedad burguesa, liberal y democrática.

Dos siglos más tarde, en las últimas décadas del siglo $\mathrm{XX}$, hemos asistido de nuevo a una explosión asociativa. El acontecimiento ha quedado registrado en informes elaborados en distintos países. En el plano internacional, merecen destacarse los programas de investigación de la Johns Hopkins University (Civil Global Society, 2000) o los datos de la Encuesta Mundial de Valores; también en la Unión Europea se han llevado a cabo proyectos comparativos distinguiendo entre la Europa del norte y la Europa del sur (proyecto Volmed); por su parte, en Francia, para conmemorar el centenario de la ley de asociaciones de 1901, han visto la luz diversas publicaciones especializadas, así como análisis rigurosos de la evolución del mundo asociativo (Barthèlemy, 2000); en Italia, destacan las investigaciones del IREF (2000) o de la Fundación Italiana del Voluntariado; finalmente, en España, en los últimos cinco años, han aparecido diversos estudios e informes, entre los que cabe citar los coordinados por Ruiz de Olabuénaga (2000), Joan Subirats (Subirats, 1999; Informe Cecs, 1999), la Fundación Tomillo (2000), Rodríguez Cabrero (2003), Pérez Díaz y Pérez Novo (2003) y García Delgado (2004). 
Este fenómeno (proliferación de asociaciones) y los cambios asociados que han experimentado las modalidades de intervención y de afiliación, las relaciones de las entidades con el Estado y con la sociedad, permiten avanzar la hipótesis de que se ha producido un verdadero giro histórico ${ }^{2}$. Sin embargo, sobre el mismo inciden distintas interpretaciones o discursos.

Unas de ellas, desde un horizonte utópico, hablan de una nueva era de la participación y profundización de la democracia. Sostienen que, en un contexto de crisis de la participación política (desafección y caída de la afiliación a partidos, sindicatos y asociaciones vecinales, volatilidad del voto y vaivenes electorales, crítica de la burocracia y de las grandes organizaciones, etc., hechos que se interpretan como una crisis del sistema de representación partitocrática), este auge asociativo expresaría una búsqueda de alternativas al desencanto y a la apatía políticas, mediante fórmulas de participación no convencional. La democracia participativa reemplazaría o, por lo menos, complementaría o profundizaría la democracia representativa; en el voluntariado podría detectarse una esperanza de sustitución de la militancia política clásica. En los movimientos y asociaciones, renacería una ciudadanía política activa ${ }^{3}$.

Otras interpretaciones, desde una perspectiva crítica que se asienta en una defensa de la producción pública del bienestar y de la garantía de la universalidad de los derechos, consideran que existe una relación sospechosa entre el ascenso del asociacionismo y la crisis del Estado de bienestar. En el denominado «retorno de la sociedad civil» o la defensa de la construcción de la sociedad del bienestar frente al Estado, no se expresa solamente, ni siquiera de forma preponderante, un reconocimiento de la necesidad de constituir una ciudadanía madura, participativa y deliberativa que contribuya, mediante el ejercicio de la libertad de asociación, a la institucionalización de derechos y a la universalización del bienestar, sino un «endose hacia la comunidad» de las medidas para paliar los efectos perversos que resultan de la entronización del mercado como primer regulador social. El discurso voluntarista, el altruismo ingenuo de algunas gentes y la ideología neocomunitarista, servirían de "coartada» para el desmantelamiento del Estado de bienestar, con las consecuencias que de ello se derivan, como son la precarización de servicios, la generación de economías

2. Se discute sobre si se trata de una mera cuestión de visibilidad o de novedad histórica: «Tal vez lo nuevo en este fenómeno no sean tanto su realidad y su dimensión sociales, cuanto su "estructuración" y su "institucionalización formalizada". Asistimos a un fenómeno antiguo reestructurado de forma diferente» (Ruiz de Olabuénaga, 2002: 268-269). Rasgos de esta reestructuración serían: secularización, mutación de la cultura moral subyacente, que pasa de la caridad y la asistencia a la solidaridad y la inclusión; individualización o reforzamiento de derechos individuales.

3. Un buen resumen de estos planteamientos puede encontrarse en la obra de M. Barthèlemy (2000) recientemente traducida al castellano por la Fundación de la Solidaridad y el Voluntariado de la Comunidad Valenciana. Como afirma Béjar, la nueva filantropía sería «la prueba de una participación que renace» (2001: 20). "Considero al voluntariado como la expresión de una nueva virtud en la comunidad asociativa de una república moderna» (Béjar, 2000: 215). 
subterráneas o la eliminación de puestos de trabajo ${ }^{4}$. Muchas de las organizaciones que han surgido en los últimos tiempos no serían más que resultado de una estrategia deliberada de transferencia a la sociedad civil de responsabilidades gestionadas otrora mediante la intervención pública: instrumentos para la oferta de servicios a bajo coste. La vibrante retórica de la autonomía de la sociedad civil y la defensa de ésta frente al Estado y sus ineficiencias no sería sino una forma de legitimación de dicha estrategia neoliberal.

Una tercera perspectiva, que se podría denominar «integrada», estaría presente en los teóricos del tercer sector o del retorno de la sociedad civil. Sostienen éstos que, en el auge del asociacionismo, se pone de manifiesto la creciente institucionalización de un sector junto a y complementario del Estado y del mercado. El bienestar tiene una producción cada vez más plural, y la contraposición tradicional entre una esfera pública y otra privada resulta insuficiente para expresar la complejidad de las sociedades modernas, donde la mayor visibilidad y creciente proliferación de organizaciones no lucrativas muestran que existe un tercer espacio definido por el rechazo tanto de la lógica meramente mercantil (la ganancia y el beneficio) como de la lógica impersonal, burocrática y opaca de la coerción formal. El tercer sector sería el campo social floreciente del altruismo, de la donación voluntaria y libre; el espacio propio de la sociedad civil y donde se cultiva el capital social que da fortaleza a una sociedad 5 .

Asideros no les faltan a unas y otras de las citadas interpretaciones. Su punto débil radica, a mi juicio, en que cada una de ellas se fija solamente en una parte del espectro asociativo o en algunas de sus tendencias. Los utópicos se centran en el voluntariado cívico y en las asociaciones y movimientos con causa; los críticos dirigen preferentemente su mirada hacia las organizaciones que prestan servicios a personas con carencias y que progresivamente han ido adquiriendo una fisonomía empresarial; los integrados homogeneizan ese tercer espacio intentando captar la lógica que subtiende a la multiplicidad de organizaciones por contraposición con el mercado (lucro) y el Estado (burocracia impersonal).

En lo que sigue, pretendo aportar evidencia empírica que pone parcialmente en cuestión cada una de esas interpretaciones o, dicho de otra manera,

4. Luis Enrique Alonso afirma: «hay que reconocer que tanto a nivel nacional como internacional, el discurso voluntarista ha servido más de coartada para el desmantelamiento del Estado de bienestar que de alternativa auténtica a los problemas de bienestar y cooperación a todos los niveles. El empleo generado en este sector voluntario sólo será consistente y real si pasa por un principio universalista de institucionalización, reconocimiento y consideración que vaya más allá de las acciones particulares de grupos aislados» (2000: 148-149). La relación estrecha entre auge del tercer sector y mutación del Estado de bienestar se halla explorada en detalle en el reciente estudio coordinado por Gregorio Rodríguez Cabrero sobre Las entidades voluntarias de acción social en España. Informe General (2003).

5. En su estudio sobre el caso español, afirma Ruiz de Olabuénaga que «Los resultados dados a conocer recientemente sugieren, por el contrario, que el caso español, tanto en términos de número de entidades no lucrativas como de volumen de empleo generado y de volumen económico gestionado, es muy similar, en términos relativos, al de Francia, Italia, Alemania o Austria» (2002: 277). 
que reconoce su validez sectorial, para una parcela específica del mundo asociativo. Considero que una investigación de estos asuntos debe partir de una ampliación del foco: se debe estudiar, en primer lugar, la totalidad del mundo asociativo para captar las lógicas y los factores que operan en él. Si actuamos de esta guisa, descubriremos que existe un notable contraste entre la visibilidad mediática y académica de determinadas asociaciones y las tendencias predominantes en el mundo asociativo, donde se da una preponderancia de las entidades expresivas y de sociabilidad.

En segundo lugar, este mundo asociativo es tremendamente heterogéneo y se halla internamente muy fragmentado y atomizado. Hoy por hoy, resulta imposible hablar de la existencia de un tercer sector, porque carece de una mínima articulación y coherencia.

En tercer lugar, la pluralidad de motivos de los asociados, la escasa participación interna y la ausencia de proyecto político en muchas entidades hace difícilmente imaginable el mundo asociativo en su totalidad como una alternativa a la participación política clásica.

Sin embargo, todas estas objeciones de fondo no pueden llevarnos al desconocimiento de: a) la aparición de tendencias a la articulación (plataformas, coordinadoras, etc.); b) la demanda de espacios de participación ciudadana (consejos, foros, etc.); c) la presencia de una creciente impregnación del vocabulario asociativo con motivos de solidaridad y responsabilidad comunitaria (una sociabilidad compasiva); d) la vitalidad de un sentido de la autonomía y de la crítica política, y e) la función que desempeñan las organizaciones en la transformación de las preferencias de los individuos.

La evidencia empírica en que sustentaré mis aseveraciones procede de varias investigaciones realizadas en la Comunidad Valenciana en los últimos tres años. Éstas tenían un carácter instrumental, derivado de su naturaleza de informes elaborados para responder a encargos de instituciones que tienen como objetivo el fomento del voluntariado y del asociacionismo. La información ha sido reunida tanto mediante técnicas cuantitativas que permiten una observación macro, como mediante técnicas cualitativas que posibilitan una observación micro o de nivel medio (meso) ${ }^{6}$. Aquí se seleccionan, se retoman y se reinterpretan exclusivamente los datos referidos a aquellos aspectos que conciernen a la argumentación del artículo.

6. Véase Ariño, A. (dir.); Castelló, R.; Llopis, R. (2001), donde aparecen referencias a los diversos estudios realizados hasta ese momento bajo el patrocinio de la Fundación Bancaja. A ellos habría que añadir la investigación sobre el fenómeno asociativo de la comarca de l'Horta Sud, publicada recientemente con el título L'associacionisme a l'Horta_Sud y la investigación en curso titulada El porvenir del altruismo, que explora las expectativas y perspectivas de futuro de las organizaciones de voluntariado de la Comunidad Valenciana (Fundación para la Solidaridad y el Voluntariado de la Comunidad Valenciana). 


\section{Multiplicidad de factores generadores de asociatividad y predominio de la sociabilidad}

Generalmente, los estudios sobre asociacionismo se caracterizan por un sesgo sectorial. Pese a estudiar preferentemente (o exclusivamente) determinado tipo de asociaciones, establecen generalizaciones sobre la totalidad del campo asociativo. Las asociaciones - se dice- son fuentes de capital social, espacios de aprendizaje de la democracia, etc. En contraste con estos abordajes, postulamos una perspectiva que trata de ser omniabarcante y que pretende captar la heterogeneidad del universo objeto de estudio. La investigación realizada en la comarca de l'Horta Sud ${ }^{7}$, del área metropolitana de la ciudad de Valencia, nos ha permitido ponerla en práctica. Esta comarca cuenta con 20 poblaciones y 375.000 habitantes. El objetivo del estudio, patrocinado por la Fundación Caixa de Torrent, entidad que promociona el asociacionismo y los recursos de la sociedad civil en la comarca, era conocer la diversidad, complejidad y vitalidad de su asociacionismo. En la guía confeccionada para la realización del trabajo de campo, hemos podido constatar la existencia en activo de 1.320 asociaciones, de las cuales hemos entrevistado a 285, así como a técnicos y cargos públicos municipales ${ }^{8}$. Por tanto, podríamos hablar de que se ha utilizado un enfoque meso o cualitativo extensivo (cuadro 1).

Tras una primera aproximación exploratoria, hemos considerado oportuno clasificar este universo en diez tipos o categorías: organizaciones culturales y educativas; festivas; deportivas; de defensa cívica; de salud; de convivencia; de solidaridad internacional; de servicios sociales; ambientales, y de desarrollo y promoción comunitaria. Al distribuirlas en las correspondientes categorías, se observa que existe una notable asimetría entre sectores, es decir, que el número de asociaciones por sector presenta grandes disparidades, y la capacidad de captar afiliaciones también es muy diversa.

En concreto, el sector de educación y cultura cuenta con el $29 \%$ de las asociaciones; le sigue el de deportes, con el 22\%, y el festivo, con el 20,7\%. Estos tres sectores, por sí solos, reúnen el $72 \%$ de las asociaciones de la comarca. En cuarta posición aparecen las que podemos categorizar como convivenciales o de sociabilidad (de jubilados; de niños y jóvenes, y de amas de casa). El resto de categorías asociativas presentan unos porcentajes muy bajos.

Las asociaciones con una afiliación total estimada más alta son las del campo de la convivencia: asociaciones de jubilados; de niños y jóvenes y de amas de

7. El trabajo de campo ha sido realizado por María Albert Rodrigo, con la colaboración de Elena Gadea y M. José Gómez. Para una síntesis de los principales resultados, véase ARIÑO, A.; Albert Rodrigo, M. (2001), L'associacionisme a l'Horta Sud, Fundación para el Desarrollo de l'Horta Sud.

8. Únicamente quedaron excluidos de nuestro centro de interés los partidos políticos, los sindicatos y las organizaciones corporativas (de empresarios, comerciantes o profesionales); en el primer caso, por considerar que se trata de organizaciones que se ubican en el campo del primer sector (Estado) y en el segundo, de entidades que pertenecen por su propia lógica al campo del segundo sector (el mercado). 
Cuadro 1. Número y tanto por ciento de asociaciones por tipos en la comarca de l'Horta Sud.

\begin{tabular}{lcc}
\hline & Asociaciones & $\%$ \\
\hline Educación y cultura & 384 & 29,0 \\
Deportes & 290 & 22,0 \\
Fiesta & 274 & 20,7 \\
Convivencia o sociabilidad & 137 & 10,3 \\
Defensa cívica & 83 & 6,2 \\
Servicios sociales & 54 & 4,0 \\
Solidaridad internacional & 32 & 2,3 \\
Salud & 30 & 2,3 \\
Medioambientales & 17 & 1,2 \\
Desarrollo y promoción comunitaria & 14 & 1,0 \\
Desconocido & 5 & 1,0 \\
\hline Totales & 1.320 & 100 \\
\hline
\end{tabular}

Fuente: elaboración propia.

casa. Dado que hay 137 entidades registradas en la guía como pertenecientes a este campo y que cuentan con una media de 498 afiliaciones por entidad, habría 68.000 afiliaciones estimadas en la comarca. A cierta distancia de este campo, y con una estimación que se sitúa en torno a las 50.000 afiliaciones, aparecen otros dos sectores: educación y cultura, y fiesta.

Con un número total de afiliaciones bastante inferior, que oscila de 20.000 a 35.000, se registran dos sectores: las entidades deportivas y las de defensa cívica.

Por debajo de las 10.000 afiliaciones e incluso con afiliaciones totales inferiores a 1.000, encontramos justamente aquellos sectores que tienen una dimensión más altruista: servicios sociales, solidaridad internacional, salud, medio ambiente y promoción comunitaria (gráfico 1).

Es decir, que si situamos los tipos asociativos en un eje cuyos polos sean la sociabilidad y la solidaridad, o la orientación convivencial endocéntrica y la orientación altruista, observaremos que existe un predominio claro de la primera sobre la segunda.

A estos datos de estructura, hay que añadir uno de tendencia. En el Registro General de Asociaciones de la Provincia de Valencia, consta que durante la década de 1990 se habían inscrito en el mismo 1.310 asociaciones en la comar$\mathrm{ca}^{9}$. Se trata de un registro de natalidad asociativa solamente, por tanto, no

9. El vaciado de los datos del Registro de Asociaciones de la Provincia de Valencia ha sido realizado por Pedro García Pilán. 


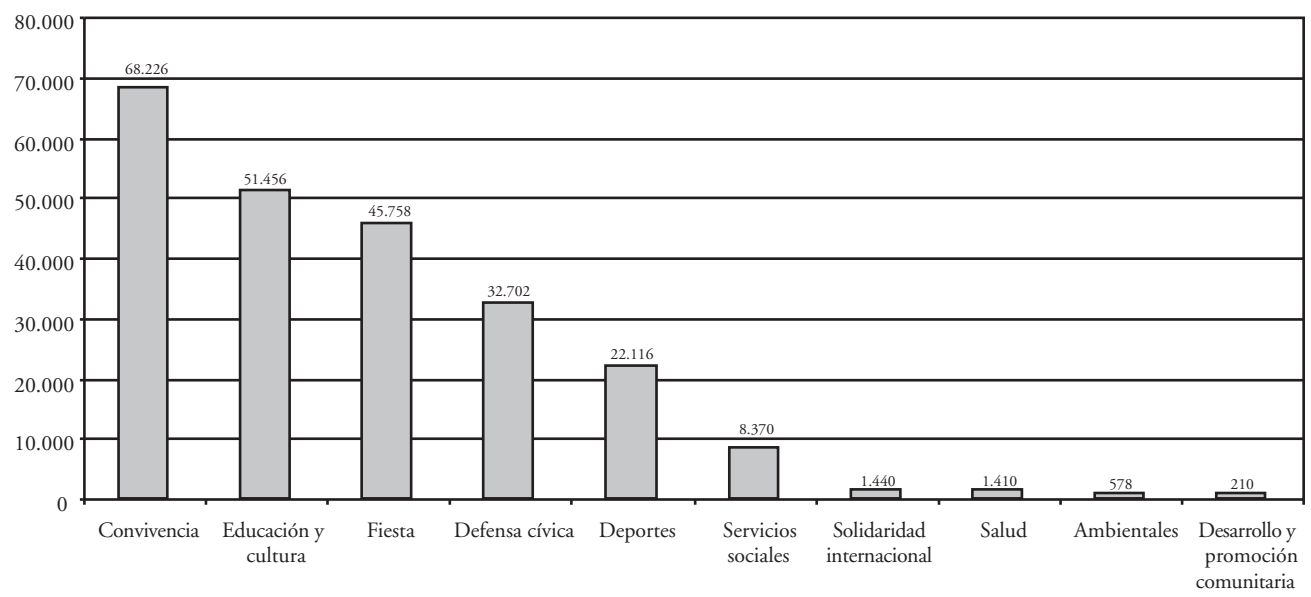

Gráfico 1. Proyección de afiliaciones sobre total de asociaciones por campo de actuación.

Fuente: Elaboración propia.

sabemos cuántas ni cuales han permanecido activas, aunque es obvio que un número importante de ellas no tiene actividad, porque su localización ha sido imposible, pese al ensayo de diversas tentativas. Sin embargo, ese dato es indicativo, en primer lugar, de la existencia de una sensibilidad y una proclividad asociativa; en segundo lugar, al estudiar esta propensión asociacional por sectores, se observa que el $26 \%$ de ellas se han inscrito como culturales o festivas; un $20 \%$, como deportivas; un $13,5 \%$, como juveniles, y un $12,3 \%$ son recreativas y de aficionados. Sólo el 4,7\% son de asistencia social y servicios sociales; un $5 \%$, de participación social; un 2,4\%, medioambientales, y tan sólo hay una asociación de cooperación con el Tercer Mundo.

Abordar el estudio del asociacionismo en su totalidad, en un espacio delimitado como es la comarca, permite captar el carácter multifactorial de la dinámica de producción asociativa, es decir que en una sociedad compleja existen múltiples fuentes de la asociatividad (tanto convivencial como productora de servicios y altruista). Hay organizaciones que prestan servicios a grupos o personas en situación de riesgo o de carencia como consecuencia del fracaso del Estado de bienestar o del mercado; otras surgen para afrontar las debilidades de la familia en un contexto de reestructuración de vínculos y de individualización, generando espacios comunes de confianza entre personas afectadas por algún riesgo, y reclaman el reconocimiento y la institucionalización de derechos (niños en acogida, enfermos de Alzheimer, exreclusos, etc.); pero también las hay, aunque sean minoritarias, que se plantean la creación y difusión de valores alternativos o de nuevos derechos (derechos culturales de las minorías o derechos de tercera generación) mediante la concienciación, la defensa de causas y la vigilancia social, y, sobre todo, hallamos organizaciones, las más 
numerosas, que ofrecen sencillamente un medio para satisfacer las preferencias de un grupo, categoría o colectivo particular en una sociedad plural, o que proporcionan enclaves para la convivencia, la reconstrucción de vínculos y la producción de identidades en una sociedad urbanizada y homogeneizadora, y que clasifica a los individuos en función de grandes categorías de edad.

En segundo lugar, a la luz de los resultados obtenidos, es indudable, pues, que en la comarca de l'Horta Sud la sociedad está vertebrada por el asociacionismo cultural y festivo; convivencial y recreativo, y deportivo. Son asociaciones que tienen que ver esencialmente con la organización y la gestión del tiempo libre. Ésta es la tendencia principal. En contraste con ella (y sólo en términos comparativos), resulta patente la debilidad relativa del resto de modalidades organizativas, sean éstas sociosanitarias o estén centradas en la defensa de causas cívicas, medioambientales o identitarias (patrimonio cultural).

Dado que la perspectiva crítica se centra en el crecimiento de las organizaciones sociosanitarias, como contrapeso y coartada a la crisis del Estado de bienestar, efectuaremos algunos comentarios sobre este tipo de asociaciones. En la comarca, y claramente también en toda la Comunidad Valenciana, ciertamente, el sector público tiene una presencia insuficiente en relación con diversas carencias y vulnerabilidades, y algunas de sus prestaciones son escasas y de deficiente calidad ${ }^{10}$. Tal vez, las insuficiencias más clamorosas pueden ser las que tienen que ver con la enfermedad mental, las demencias seniles y la atención a la dependencia de las personas mayores, aunque en ciertos barrios también se dan situaciones de carencia de recursos básicos, fracaso escolar, etc. Pues bien, existen algunas asociaciones, inicialmente formadas por familiares, enfermos y profesionales inquietos, que tratan de prestar servicios en estos campos, pero el reducido número de ellas y su menguada afiliación permiten afirmar que apenas constituyen un complemento, sin duda digno de elogio, que tapa algunos de los agujeros del Estado de bienestar, pero que, dada su reducida implantación, sigue sin cubrir la incidencia y el alcance de las deficiencias fundamentales. Nadie podría afirmar que constituyen (o constituirán) un sustituto creíble del Estado de bienestar. Ponen una tirita en un cuerpo plagado de llagas.

¿Cómo y por qué surgen? Muchas de estas entidades han sido creadas por familiares de las personas afectadas, como redes de ayuda mutua, que logran consolidarse y formalizarse a duras penas. Con el tiempo, algunas se estructuran como cooperativas de trabajo asociado que mantienen contratos relativamente estables (o, lo que es lo mismo, relativamente discrecionales) con la Administración. ¿Cuál es su filosofía? Lejos de reivindicar el retorno de la sociedad

10. Al respecto, pueden consultarse los datos de la macroencuesta realizada por el INE, la ONCE y el IMSERSO sobre discapacidades y dependencia en España. Específicamente, para la Comunidad Valenciana ver ARIÑO, A. (dir.), La rosa de las solidaridades. Necesidades sociales y voluntariado en la Comunidad Valenciana, Bancaixa, 1999. En el caso, por ejemplo, de prestaciones para personas mayores, pueden consultarse los informes anuales del Imserso o los de la Sociedad Española de Geriatría y Gerontología. 
civil y postular una cultura de la subsidiariedad, defienden la responsabilidad del Estado («hacemos lo que debería hacer el Estado»); consideran que las asociaciones realizan una tarea que le compete al sector público («Yo quisiera que desapareciera la asociación, que no hiciera falta»), pero el carácter dramático de la situación, la urgencia de la necesidad y el sentido de la responsabilidad moral les incita a dar una respuesta mediante la práctica asociativa.

Por otra parte, son conscientes de que a la debilidad crónica del Estado de bienestar en el Estado español, ha venido a sucederle en los últimos años una abdicación en la provisión de servicios, una privatización de los mismos, delegándolos en parte a organizaciones no lucrativas. En este contexto, en los grupos de autodiagnóstico realizados durante los meses de mayo y junio en diversas comarcas ${ }^{11}$, hemos observado que se perfilan dos posiciones diferentes y que sobre los grupos planea una pregunta inquietante.

Una posición, que muchos perciben como una amenaza grave y que les lleva a debates tensos en el seno de las asociaciones, pero que otros experimentan como una oportunidad, es la que consiste en una adaptación a la lógica del Estado jibarizado. Las entidades modifican sus objetivos, por ejemplo, en función de la orientación de las subvenciones y las líneas programáticas que prima la Administración. De esa forma, entran en una cadena de institucionalización, profesionalización y empresarización, que culmina generando pautas de conformidad. En ellas, se da un desplazamiento de objetivos, que algunos miembros desde dentro, y muchas personas desde fuera, consideran una perversión de la naturaleza originaria de dichas entidades.

Una posición claramente diferente de la anterior sostiene que la función de las asociaciones consiste en detectar problemas, lanzarlos a la conciencia pública y defender derechos, con el objetivo de que éstos sean reconocidos y garantizados por el Estado. Los derechos no pueden ser graciables, afirman. Por tanto, la provisión de prestaciones debe estar garantizada de forma universal. Son decididamente defensores de lo público: el Estado debe definir derechos y normalizarlos. Cosa distinta es cómo se gestionan. Las asociaciones quieren participar en la deliberación sobre los derechos y en la toma de decisiones sobre los programas, y no sólo en la gestión. En este sentido, puede decirse que expresan un sentido de democracia participativa.

Pero, además, estas tomas de posición se producen, como se ha anticipado, en medio de un debate inquietante: ¿qué aportamos nosotros de específico?, se preguntan. En uno de los grupos de autodiagnóstico, la pregunta encontró una respuesta salvífica. Después de que los participantes dieran varias vueltas en torno a la cuestión y que coincidieran con relativa unanimidad en la res-

11. Durante la pasada primavera (2002) hemos realizado numerosas entrevistas en grupo para el estudio sobre El porvenir del altruismo, citado en la nota 5. Con ellas se pretende recoger información sobre las expectativas y demandas de las organizaciones de voluntariado, con el fin de que la Fundación de la Solidaridad y el Voluntariado de la Comunidad Valenciana pueda elaborar un plan estratégico del sector para los próximos años. 
ponsabilidad del Estado, una voluntaria de una organización dedicada a cuidar a niños con tumores cancerosos se expresó en los siguientes términos:

Yo estoy de acuerdo en que la Administración pública no cubre toda la atención que hacemos las asociaciones, que es una atención más de cerca, con gente que conoce bien el tema, que está metida porque a lo mejor ha sido afectada, y conoce muy bien y de cerca la realidad, entonces eso es lo que muchas veces se le escapa a la Administración..., también creo que aunque la Administración pública cubriera perfectamente la atención que damos las organizaciones, pienso que las asociaciones deberían seguir existiendo, que las asociaciones no están ahí sólo para hacer lo que falta por cubrir de la Administración, sino que están ahí para cumplir un papel societario, que somos una sociedad relacional..., y creo que hay cosas que la Administración no podrá cubrir porque no son sólo necesidades que se tiene, sino el contacto con personas que han pasado por lo mismo, o simplemente el sentimiento de, nosotros por ejemplo con los niños con cáncer, tenemos un programa de voluntariado de apoyo en el hospital, que es un poco dar entretenimiento a los niños, entonces va gente joven aunque sea un ratito a estar con ese niño, a jugar con ellos, a sacarle una sonrisa, eso no lo puede pagar la Administración ni lo puede pagar nadie, porque eso son las personas que vivimos en sociedad que tenemos algo que dar y algo que aportar, no va a ser todo la Administración, nosotros también tenemos mucho que dar, de nuestro tiempo, no de nuestro dinero, ya eso lo damos con los impuestos, darnos parte de nosotros y parte de nuestro tiempo y pienso que eso es fundamental, porque eso es un trabajo que hacen las asociaciones y que debe de continuar aunque lo cubra todo la Administración (Entrevista de Grupo, ciudad de Alicante).

El asentimiento que una interpretación de estas características suele obtener en los grupos es unánime, porque en ella se verbaliza la lógica de un campo de acción que tiene dificultades para expresarse en una sociedad impregnada por la lógica del mercado y por el vocabulario del individualismo posesivo y utilitario, como muestran diversos estudios (Wuthnow, 1991, o Béjar, 2001). Sin embargo, como ha sostenido recientemente Boltanski (2000), para entender adecuadamente la sociedad se requiere el reconocimiento de la existencia de distintos regímenes de acción, uno de los cuales es el del amor o del ágape, que se manifiesta por la gratuidad y por la renuncia al cálculo ${ }^{12}$.

La explicación del auge del asociacionismo no puede quedar reducida, pues, a una coartada del Estado de bienestar en fase de derribo o una prolongación, por otros medios, de la lógica del individualismo posesivo. Esto no significa desconocer, sino ponderar adecuadamente, la existencia de un desplazamiento de objetivos en algunas organizaciones (y la presencia de otras constriccio-

12. Si en el campo del asociacionismo de voluntariado social, la lógica interna estructurante e irreductible sería el ágape, podemos añadir que en otros campos asociativos donde las entidades lindan con los movimientos sociales, la lógica interna se estructura en torno a la formación y emergencia de la conciencia. Véase, al respecto, el fragmento de entrevista transcrito en la nota 17. 
nes), como resultante de la tendencia a la externalización de prestaciones por parte de la Administración pública. E igualmente se detecta entre los voluntarios la presencia de un vocabulario de motivos impregnado de individualismo, más o menos utilitario, según los casos, o más o menos expresivo.

\section{La heterogeneidad en el seno del altruismo}

De modo similar, también debe ser reevaluada la tesis de la aparición de una sociedad civil articulada en torno al tercer sector. Si al hablar así, de tercer sector, se quiere dar a entender que existe un universo abigarrado de entidades cuya lógica social (voluntariedad, libertad de pertenencia, altruismo y donación) se distingue de las lógicas que operan en las relaciones adscriptivas, en las relaciones de mercado (comunidades de intereses) y en las relaciones con el Estado (basadas en la coerción formal), el concepto tiene validez. Pero una validez limitada, sin duda, puesto que voluntariedad y libertad de pertenencia, altruismo y donación, son lógicas concurrentes, que generan campos de acción con zonas de solapamiento, pero no son exactamente coextensivas.

Las organizaciones que componen este universo, denominado «tercer sector", son extremadamente heterogéneas. Podemos asomarnos a algunos aspectos de dicha heterogeneidad centrándonos en el sector que supuestamente podría estar más articulado, el mundo del denominado «voluntariado social». Estas organizaciones difieren por su historia y por sus objetivos (hay entidades de afectados, de voluntarios, que nacen de un fuerte liderazgo, o que son propiciadas por instituciones como una parroquia o un ayuntamiento); son divergentes en función de factores estructurales (orientación a los miembros o a terceros) e ideológicos (matriz credencial: laica y aconfesional); cuentan con recursos muy diversos (tanto humanos como materiales) y gozan de grados muy distintos de autonomía financiera ${ }^{13}$.

Podemos explorar esta disparidad utilizando los datos de una encuesta realizada a 500 organizaciones de la Comunidad Valenciana, en el año 2000, en el marco de un estudio patrocinado por la Fundación Bancaja para conocer las características más destacadas del voluntariado valenciano ${ }^{14}$. Un primer análisis descriptivo de los resultados obtenidos en las distintas preguntas ya permite captar esta situación: heterogeneidad basada en factores genéticos (de quién procede la iniciativa de creación de las entidades), estructurales (según

13. En un artículo reciente, Wilson ha subrayado también esta heterogeneidad. Afirma, al respecto, que el término voluntariado abarca un extenso repertorio de actividades muy diversas y que puede resultar poco útil tratar de explicarlas todas con la misma teoría (Wilson, 2000: 233).

14. Para la selección de la muestra de las organizaciones a entrevistar, se creó primero una base de datos con las organizaciones de voluntariado inscritas en diversos registros y guías. Se entiende por organizaciones de voluntariado aquéllas que se orientan a la producción de un bien colectivo y se inscriben en guías de voluntariado. Para una descripción detallada de la metodología, de las técnicas y de los resultados, véase Ariño, A. (dir.); Castelló, R.; Llopis, R. (2001). 
su orientación hacia dentro o hacia fuera), ideológicos o credenciales (matriz religiosa o laica); diversidad fundada en características relativas a sus recursos humanos (estructura y tamaño); disparidad en sus fuentes de financiación (autónoma, sociedad civil, pública). Sin embargo, dada la masa de información obtenida, se ha construido una tipología, capaz de agrupar los datos más relevantes, mediante la realización de un análisis de conglomerados. El análisis ha procedido en dos pasos: en el primero, se han utilizado las variables número de voluntarios, tamaño del presupuesto y presencia en el mismo de la financiación pública ${ }^{15}$. Se han obtenido cuatro grupos que, a su vez, han sido tomados en consideración como variables para un segundo paso, en el que se han introducido también las variables iniciativa de creación, orientación estructural y matriz credencial. Hemos obtenido finalmente seis grupos diferentes de organizaciones que reúnen las siguientes características ${ }^{16}$ :

1) El primer grupo, que denominamos «entidades de ayuda mutua», se caracteriza por estar conformado casi exclusivamente por organizaciones creadas por iniciativa de afectados o familiares (el 99\% del conglomerado), con una presencia muy importante de la orientación a los miembros $(71 \%)$ y una matriz credencial laica (90\%). En ellas, hay una presencia importante de organizaciones con pocos voluntarios, poco presupuesto y una financiación pública destacada (48\%). La característica más sobresaliente de este conglomerado sería, pues, la ayuda mutua.

2) El segundo grupo se caracteriza por su matriz credencial religiosa o de inspiración católica ( $100 \%$ de las organizaciones de esta agrupación), por una presencia relevante de la iniciativa parroquial en su creación (69\%) y por su orientación a terceros $(90 \%)$. Es notorio que se trata de un conglomerado de organizaciones con una base religiosa importante, así como con una vocación de servicio a los demás también destacada. Por ello, hemos optado por denominarlas «entidades de voluntariado de altruismo católico".

3) En el tercer grupo encontramos a la mayoría de las organizaciones que pertenecen al tipo de poco presupuesto, pocos voluntarios y mucha financiación pública (85\%); además, son entidades con una matriz credencial laica $(93 \%)$ y una orientación a terceros $(81 \%)$. Dada la importancia de la financiación pública, así como de la iniciativa de creación administrativa, tan relevante en este grupo, creemos que nos encontramos ante una categoría

15. Los valores de las variables introducidas son: 1) Número de voluntarios: $0-3$, siendo 0 equivalente a la ausencia de voluntarios; 1 , a una presencia entre 1 y 10 voluntarios; 2 , de 11 a 50, y 3, más de 50 voluntarios; 2) Participación de la financiación pública: 1-4, siendo 1 equivalente a una participación baja entre el 0 y el $24 \%$; 2, entre el $25 \%$ y el $49 \%$; 3, entre el $50 \%$ y el $74 \%$, y 4 , más del $74 \%$; 3) Tamaño del presupuesto: $1-4$, siendo 1 equivalente a un presupuesto bajo entre 1 y 4 millones; 2 , un presupuesto entre 5 y 15 millones; 3 , un presupuesto entre 16 y 50 millones, y 4 , un presupuesto superior a 50 millones.

16. Los resultados obtenidos pueden consultarse en el anexo 1. La realización de este análisis corrió a cargo de Rafael Castelló i Cogollos. 
que puede ser definida como «entidades de voluntariado de vinculación administrativa».

4) En la cuarta agrupación se sitúan organizaciones caracterizadas por la iniciativa carismática del liderazgo (79\%), por una orientación principalmente a terceros $(78 \%)$. De hecho, el matiz más significativo que diferencia este grupo de los demás se encuentra en la iniciativa del liderazgo. Por ello, hemos optado por denominar a este grupo «entidades de voluntariado de liderazgo».

5) En la quinta categoría, las organizaciones destacan por su poco presupuesto y poca participación pública (100\%), por la iniciativa de creación de voluntarios $(76 \%)$, una orientación a terceros $(82 \%)$ y una matriz laica $(93 \%)$. Dada la importancia de la iniciativa cívica y de la escasa financiación pública, sería el correlato opuesto del grupo 3, por lo cual hemos decidido llamar a las organizaciones de este grupo «entidades de voluntariado de iniciativa cívica».

6) Finalmente, la sexta categoría se caracteriza por su orientación exclusivamente a terceros (91\%), su matriz credencial laica (93\%), su elevado presupuesto $(89 \%)$, sea con mucha financiación pública y pocos voluntarios (41\%), sea con muchos voluntarios y menos financiación pública (48\%). El atributo que con mayor fuerza destaca en este grupo es la dedicación exclusiva a terceros, que, junto a la matriz laica, lo sitúan en el equivalente laico de las entidades de voluntariado de altruismo católico del grupo 2, por lo que hemos decidido denominarlo «entidades de voluntariado de altruismo laico».

¿Cuál es su distribución? En primer lugar, aparece una diferenciación fundamental entre entidades de ayuda mutua (35\%), entidades altruistas (19\%) y entidades mixtas (46\%). En segundo lugar, dentro de la orientación altruista, hay que distinguir entre el altruismo católico (10\%) y el altruismo laico (9\%), que responden a culturas de la acción social muy diferentes, y que presentan, por cierto, porcentajes muy similares. En tercer lugar, dentro de las entidades mixtas, se puede distinguir entre una iniciativa cívica grupal (9\%), carismática o de liderazgo individual (15\%), y una estrecha vinculación institucional (organizaciones paraadministrativas) (22\%).

Como puede observarse en el cuadro 2, en líneas generales, se da una correlación estrecha entre los tipos que surgen de este análisis de conglomerados y las especializaciones relativas de las organizaciones: las entidades de ayuda mutua se dan predominantemente en el campo de la salud y de la atención a discapacitados; el altruismo católico y el altruismo laico, en el campo del bienestar social; el voluntariado de vinculación pública, en la cooperación al desarrollo y la protección de bienes culturales; la iniciativa cívica, en la protección al medio ambiente y la defensa de derechos humanos, y el liderazgo, en la protección de bienes culturales.

Vemos, pues, que existe una gran disparidad, derivada, entre otros factores, del tipo de objetivos que han de atender las organizaciones, aunque no 
Cuadro 2. Tipos de organizaciones de voluntariado según análisis factorial, su distribución porcentual y su especialización relativa.

\begin{tabular}{lcl}
\hline Tipología organizativa & Distribución en \% & Especialización relativa en campo \\
\hline $\begin{array}{l}\text { Entidades de ayuda mutua } \\
\text { Entidades de voluntariado }\end{array}$ & 35 & Salud y discapacitados \\
de: Vinculación pública & 22 & Cooperación al desarrollo y protección de bienes culturales \\
Liderazgo & 15 & $\begin{array}{l}\text { Protección de bienes culturales } \\
\text { Iniciativa cívica }\end{array}$ \\
& 9 & $\begin{array}{c}\text { Protección del medio ambiente y defensa de los derechos } \\
\text { humanos }\end{array}$ \\
Altruismo católico & 10 & Bienestar social \\
Altruismo laico & 9 & Bienestar social \\
\hline
\end{tabular}

solamente de ellos. Lo que el investigador encuentra es un universo disperso y fragmentado, en el que brillan algunas grandes organizaciones pero pululan, como en un vivero, infinidad de pequeñas, diminutas, entidades, de carácter local, orientadas a lo próximo.

Si bien esta heterogeneidad se puede entender, en principio, como un factor de riqueza del sector, que tiene una gran capacidad adaptativa a las distintas circunstancias, que sabe utilizar y movilizar recursos procedentes de las solidaridades primarias (familia, afectados, amistad), que atiende a las demandas directas y especializadas, también se puede considerar, con Melucci, que constituye una debilidad: la heterogeneidad deriva en fragmentación y atomización; la concreción de objetivos, en pérdida de un horizonte o proyecto transformador a largo plazo, y refleja una incapacidad para leer en clave política los riesgos y las vulnerabilidades que atienden (Melucci, 1983: 15-16). En la situación del mundo asociativo confluyen distintos factores de debilidad: la escasez de relaciones entre las entidades, la dualidad de lógicas y de culturas (producción de valores-prestación de servicios, cultura de la subsidiariedad-táctica de la vigilancia y control), y la fragilidad de las relaciones con la sociedad y con el Estado.

Las relaciones entre entidades son muy débiles. Apenas existe coordinación vertical (dentro de un sector) o transversal (entre sectores en una misma localidad o espacio). En ocasiones, no se conocen entre sí; en otras, no se reconocen o se ignoran y se hacen la competencia («nos vigilamos a ver cuál obtiene más subvenciones»).

Las organizaciones que prestan servicios a personas en situaciones de riesgo, vulnerabilidad o carencias, apenas mantienen relación con aquéllas otras dedicadas a defender causas: sean asociaciones de vecinos, de acogida de inmigrantes, de derechos humanos, etc. Se trata de dos mundos que siguen trayectorias divergentes: las primeras, orientadas a la prestación de servicios a personas, tienden a la profesionalización y a la empresarización, se apoyan más en el trabajo profesional que en el voluntario, necesitan la regularidad de la financiación procedente de la Administración pública, y en el proceso de reconoci- 
miento institucional, tienden a eludir la manifestación de la crítica; las segundas, orientadas a la denuncia y la transformación, se apoyan en el trabajo cívico voluntario, con escasa profesionalización y reducidos presupuestos, tienden al control de las actuaciones tanto de la Administración como de las empresas.

Pero, para concluir el argumento de esta sección, conviene recordar de nuevo que en la construcción de esta tipología sólo hemos contado (por la limitación de los datos) con las entidades que trabajan en el campo del denominado «voluntariado social». La heterogeneidad, diversidad y disparidad serían aún mayores al incorporar las asociaciones que trabajan en el campo de la sociabilidad y convivencia, del deporte y el ocio o de la fiesta, es decir, todas aquellas, fundamentalmente autocentradas, que pueden ser consideradas como comunidades de práctica de diverso tipo.

\section{Apatía política y participación cívica}

Todas las asociaciones, lo quieran o no, se encuentran insertas en la dimensión política de la vida social y su acción tiene consecuencias políticas, con independencia de que tengan o no conciencia de ello. Pero sólo algunas entidades poseen un proyecto político explícito, es decir, definen sus objetivos y reclaman un reconocimiento público y legitimidad para su acción, con el propósito de mejorar o transformar el mundo. En ese sentido, también puede decirse que todas las asociaciones están compuestas por ciudadanos, pero sólo en algunas hay un discurso y una práctica de la ciudadanía cívica. En consecuencia, la tesis de que las asociaciones reflejan las expectativas de participación cívica o de que en la proliferación actual se pone en juego un modelo de ciudadanía participativa, debe ser revisada o matizada. Las asociaciones, per $s e$, no son escuelas de democracia, espacios de transformación del individuo en ciudadano, o de definición de las carencias, los riesgos y las vulnerabilidades en términos sociales y políticos.

Dos estudios recientes cuestionan precisamente la tesis de que en el asociacionismo florezca una nueva era de la participación. Nina Eliasoph, que efectuó trabajo de campo durante dos años y medio entre voluntarios californianos, miembros de asociaciones recreativas y activistas medioambientales, afirma: "la gente que yo entrevisté deseaba crear un sentido de comunidad, pero no deseaba hablar de política» (1998: 230). En todo caso, hablaban más de política en el ámbito privado (entre bambalinas) que en el espacio asociativo público (en el proscenio). Por ello, su estudio se centra en investigar cómo se construye en la vida cotidiana la apatía política.

Por su parte, Madeleine Barthèlemy sostiene que en el talante y la orientación del movimiento asociativo francés de las últimas décadas, más que una ciudadanía asociativa renovadora de la participación democrática, lo que subyace es una retirada de la política. Ésta se haría patente en distintos aspectos: a) en la tendencia a sustituir los referentes de largo plazo, de la transformación social y del proyecto de formación del ciudadano por la proximidad de la acción concreta, la inmediatez (lo local) y el riesgo, es decir, en la prioridad 
de lo pragmático frente a lo ideológico; $b$ ) en el ascenso del voluntariado («obrar para los otros»), que nace de una definición moral, a costa de la militancia («hacer juntos»), que nace de una definición política; $c$ ) en el incremento del interés por la gestión técnica de la vida asociativa, por la lógica empresarial y las técnicas de comunicación, más que por el análisis de las causas de los fenómenos sociales; $d$ ) en el retroceso de la dimensión conflictiva (la búsqueda de la concertación favorece una lógica consensual y el voluntariado paramunicipal más que el activismo y la movilización), y e) en la territorialización de las políticas sociales; en el clima ideológico general de despolitización y en la sujeción a las subvenciones (2000: 247).

Por otra parte, para que se pueda hablar de una ciudadanía asociativa, es preciso que se den dos condiciones: a) una interpenetración del Estado y de la sociedad en la que las asociaciones no aparezcan como exteriores frente a la sociedad política, y $b$ ) un reconocimiento por parte de las asociaciones de su responsabilidad en la definición de los valores de la esfera pública y en las carencias de las reglas democráticas. La vida real interna de las asociaciones está lejos de mostrar que en ellas haya una alternativa de democracia participativa frente a los lastres supuestos de la democracia representativa: el déficit de democracia interna en las asociaciones es real; se da una débil renovación de los cargos, una notabilización de los responsables, una rutinización de las prácticas democráticas y un incremento de la distancia entre elite y base.

¿Qué hemos encontrado nosotros en el trabajo de campo? Una situación heterogénea, sin duda. De un lado, hay asociaciones que tienen un discurso político explícito, que cuentan con lo que podríamos denominar, de acuerdo con Barthélemy, un "proyecto político fundacional», que se presentan a la sociedad con el propósito de cambiar e incidir en el orden común, bien sea con un enfoque alternativo o reformador; que tratan de conectar la acción local con sus contextos más amplios y que buscan las causas sin por ello eludir la procura de los remedios inmediatos.

En el campo del medio ambiente, de la defensa cívica, entre los grupos de inmigrantes o en muchas de las asociaciones culturales, se produce una definición de la identidad de la asociación y de sus prácticas en términos explícitos de ciudadanía activa, con una distinción explícita entre toma de posiciones partidistas (que rechazan) y movilización a favor de valores alternativos (que propugnan) ${ }^{17}$.

17. Un representante de una asociación cultural afirma al respecto: «Bueno, estem constituïts com a associació cultural, però sense pretensió de ser neutrals, apolítics, ni res d'això. Tenim clar en quina opció política estem. No és que sigam tots del mateix partit polític, o siga, no partidisme, però sí una opció social que actualment se considera com a política, bueno, pues estem tots un poc en el tema antimilitarista. De fet, un dels grups que el va formar va ser el col-lectiu Milikaka. Després estem per temes ecologistes, per temes socials, de... Des de l'ajuda als pobles saharauis, sobre el barri de La Coma..., estem per un tema nacionalista, una concepció de les cultures» (comarca de l'Horta Sud).

En una línea similar, un dirigente de un centro de estudios comarcal afirmaba: «La majoria de centres d'estudis, no tots, però la majoria, naixen com a reacció davant d'un procés 
De otro lado, hay asociaciones de orientación pragmática, centradas en la producción y prestación de servicios para personas con graves carencias, que eluden la decantación política y la crítica fundamentalmente por razones tácticas (necesidad de conformarse al poder de turno para captar o mantener subvenciones, evitar represalias o poner en peligro la financiación de los programas).

En tercer lugar, se encuentran aquellas asociaciones que son netamente apolíticas. Entre ellas, es posible diferenciar al menos dos grandes tipos. Unas de ellas son apolíticas porque otorgan primacía a una definición moral de las carencias y los riegos. La adicción al alcohol o a las drogas, el fracaso escolar, la dependencia, etc. no encuentran una explicación social y política, sino estrictamente personal e individual y deben ser reparadas desde una opción exclusivamente moral. La orientación hacia lo próximo, hacia la urgencia y hacia lo realizable, suponen una evaporación de la dimensión política.

Aquí ni se habla de religión ni de política... Aquí el único propósito que hay es que se cure la gente... Lo demás, cada uno puede tener su ideología o lo que sea, pero aquí cuando se entra..., ya se sabe, aquí somos apolíticos totalmente, una vez dentro... y de ningún tipo de religión.

Pero también son militantemente apolíticas todas aquellas organizaciones en las que el objetivo central es la construcción de una experiencia de comunidad, de práctica, bien sea mediante la fiesta, el deporte, la realización de una afición cultural o la simple convivencia. En éstas, el discurso apolítico se construye, seguramente por razones estratégicas, para proteger la armonía comunitaria: la conversación sobre asuntos políticos o religiosos se toma como una intromisión disruptiva del clima amistoso y comunitario que debe presidir las actividades de la entidad. Las reglas de la etiqueta cívica prohíben la conversación sobre dichos temas y, mucho más aún, que se plasmen en algún tipo de práctica o decisión.

La mayoría de las asociaciones de sociabilidad (deportivas, recreativas, convivenciales, festivas) convergen en un planteamiento similar: la política y la religión no son asuntos que puedan ocupar la conversación abierta y menos aún el debate público en la junta de socios. Lo que importa en ellas es la evitación de todos los factores disruptivos del clima armónico que engrasa el dinamismo de la sociabilidad. Y lo que muchas personas esperan de la asociación no es otra cosa que la recomposición de un vínculo social, un espacio para la comunicación entre iguales, donde un clima amable facilite la evasión frente a

de degradació patrimonial [...] Aleshores, es tracta de combatre ixe procés mitjançant el que pot aportar un centre, digam el combat intel-lectual del procés de degradació [...] Els objectius serien contestar, a la manera que pot un intel.lectual, la degradació del patrimoni; conscienciar la població de la comarca, primer de què viu en una comarca, que té unes peculiaritats diferents d'altres comarques i després de l'important patrimoni que s'està deixant perdre si no s'actua d'immediat» (comarca de l'Horta Sud). 
preocupaciones, ansiedades y premuras, propicie la supresión de etiquetas y rangos y cada cual cuente como un ser humano.

Las asociaciones, en general, en una sociedad crecientemente individualizada, generan espacios para la reinvención de una experiencia de comunidad, para la conversación excepcional y la confianza entre amigos. En esos espacios, tienen razón Eliasoph y Barthèlemy, suele haber poca cancha para la tertulia, el diálogo y el debate políticos, para establecer un vínculo entre lo que sucede en el local asociativo y su entorno o en la sociedad más amplia. Y las asociaciones pueden convertirse en guetos, como decía uno de nuestros informantes. No se puede, por tanto, caer en una mitificación del carácter democrático del asociacionismo per se o de la ciudadanía asociativa como una alternativa al desencanto político.

Pero, ¿es eso todo?, ¿evasión?, ¿distracción?, ¿mera reinvención imaginaria de un sentido imposible de comunidad? En el ámbito del asociacionismo convivencial, detectamos al menos dos pautas que permiten registrar la existencia de experiencias que trascienden la autofinalización de la sociabilidad: una ciudadanía vigilante, aunque limitada, y una transformación de las preferencias.

Con el concepto de ciudadanía vigilante y limitada nos referimos al hecho de que la consolidación de la vida asociativa hace que las organizaciones y sus miembros desarrollen un sentido del control de la actuación de la Administración en todo lo que les concierne. Puede hablarse también de una ciudadanía corporativa, puesto que se trata de influir y mantener un espacio de influencia mediante la organización y la legitimidad que procede de ella. En medio de la apatía, constituye una forma de afirmación ciudadana, aunque limitada en su alcance y discutible desde una perspectiva de legitimidad basada en la democracia representativa.

Por otra parte, también hay que afirmar, frente a Eliasoph, que la experiencia asociativa no es sólo una experiencia discursiva o conversacional y que el hecho de que las reglas de etiqueta cívica imperantes en una asociación prohíban el debate político, fomentando, por tanto, la apatía, no implica que su acción carezca de consecuencias transformadoras. Un ejemplo, extraído de las asociaciones de amas de casa, muy florecientes y con una amplia afiliación, puede servir de ilustración al argumento. Sin duda, aunque éstas se definen como apolíticas, tienen una decantación o una afinidad electiva más bien conservadora, pero su acción, de forma imprevista, está transformando las relaciones de género en el plano doméstico y modifica tanto la autoestima como el estatus de las mujeres.

Hay personas que no salían de casa para nada y aquí (en la asociación) han encontrado un aliciente, han descubierto que bueno..., que, por ejemplo, pensaban que la pintura era para grandes pintores y han descubierto que cualquier persona está capacitada para hacer muchas cosas, te hablo de pintura o de las láminas o de estaño..., de mil historias que se hace... Entonces, la labor social que se hace es muy importante, muy importante a nivel de amas de casa, es como una terapia... Ellas vienen, se distraen, se cuentan sus romances, están dos o tres horitas..., luego hacemos una excursión, una charla, se hacen viajes 
culturales..., se hacen un montón de cosas y se pasa el tiempo..., pues eso, cosas que no hemos salido y no hemos visto, porque somos incapaces de irnos solas a ver un museo y, sin embargo, vas en grupo y descubres cosas que, madre mía, que no lo hubiéramos hecho solas. (Asociación de Amas de Casa, Comarca de l'Horta Sud)

También estas asociaciones, como las comisiones festivas y otras formas de comunidad de práctica, proporcionan un espacio para la distracción, para la evasión, para la superación de problemas, y reinventan un sentido provisorio de comunidad. Pero hay algo más, en la asociación estas mujeres descubren: a) que pueden pintar (democratización de la cultura), y b) una experiencia del mundo fundada en la sororidad: "descubres, madre mía, cosas que no lo hubiéramos hecho solas». La asociación capacita para asumir riesgos en el ámbito público y actúa como espacio de transformación de las preferencias individuales. Puede tener por sí misma, en función de su estructura, una capacidad transformadora. Si partimos de la distinción entre ámbito público, ámbito doméstico y ámbito privado, es obvio que estas mujeres tenían ámbito doméstico (Murillo, 1996), y que ahora comienzan a descubrir, gracias a y mediante la asociación, tanto el ámbito público como la construcción de su privacidad, y al hacerlo reconfiguran también las experiencias de los miembros de su hogar, muy especialmente las de sus maridos. Es obvio que debemos fijarnos con más atención y detalle en lo que sucede en estos espacios de sociabilidad, aparentemente autofinalizada, donde se exploran nuevos territorios de la experiencia existencial.

\section{La renovación de lo social}

En conclusión, las interpretaciones referidas al principio y evaluadas a lo largo de este texto (la participación asociativa y la proliferación de asociaciones como respuesta al desencanto político, el incremento del asociacionismo como alternativa a la crisis del Estado de bienestar, el auge del asociacionismo como expresión de madurez del tercer sector) constituyen buenas guías para ordenar los datos que proporciona una realidad compleja, pero son claramente insuficientes.

La investigación muestra, a partir de los datos de la comarca de l'Horta Sud, que el universo de la creatividad asociativa abarca un amplio espectro, pero también que tiene una estructura asimétrica. Durante los años noventa, se ha producido una sorprendente oleada de creatividad asociativa, que ha afectado a todos los sectores, pero en conjunto predominan las asociaciones autocentradas, sobre las más netamente altruistas o heterocentradas; las orientadas a la sociabilidad, más que las dedicadas a la solidaridad; las apolíticas más que las que adoptan una interpretación de sus objetivos en clave política y definen proyectos de intervención acordes con ello. Por tanto, existe un predominio de las comunidades de práctica, que expresan la multiplicidad de intereses y aficiones latentes en una sociedad civil plural, sobre las entidades 
prestadoras de servicios (que complementarían o sustituirían la provisión de prestaciones por el Estado) o sobre las organizaciones defensoras de causas, que expresarían la emergencia de formas nuevas de participación democrática.

No obstante, las propias entidades reconocen que, en determinados sectores, actúan como sustitutos de un Estado de bienestar en retirada y declaran sentirse instrumentalizadas por los responsables de la gestión política, pero con la misma clarividencia reconocen el limitado alcance de sus actuaciones (una tirita) y reclaman del Estado una intervención más decidida y de mayor alcance. Finalmente, desde el campo de las organizaciones heteroorientadas se reclama la especificidad de su lógica de actuación (donación altruista, creación de conciencia social) que consideran irreductible a la lógica del mercado y a la lógica de la acción pública.

En general, hemos detectado un estilo de presencia en la esfera pública de la mayoría de las asociaciones que podría denominarse "ciudadanía vigilante» (que consiste en acotar simbólicamente un territorio social y convertirse en guardianes defensores de los derechos que conciernen a los actores del mismo frente a la Administración pública); hemos mostrado que las entidades contribuyen a una redefinición de las necesidades sociales y de las formas de satisfacción de las mismas mediante políticas más abiertas, participativas y descentralizadas, que tienen la capacidad de operar una transformación de las preferencias o de los motivos de sus miembros. Movimientos sociales, entidades, líderes del mundo del voluntariado demandan que también cuente su voz, proponen la institucionalización y tutela de derechos, la promoción de la ciudadanía activa. Como afirma Alonso, en el auge asociativo alienta una visión proactiva: «se viene constituyendo con ello un espacio social, en el que se insertan una extensa y tupida red de asociaciones voluntarias que representa en última instancia la defensa real, social y cívica de unos derechos de ciudadanía consagrados por el hoy muy atacado Estado de bienestar keynesiano, así como la transformación y desarrollo mismo de estos derechos en un contexto multicultural y segmentado» (Alonso, 2001: 131) ${ }^{18}$. Pero no todo es ciudadanía activa y participativa, ni mucho menos. Las asociaciones pueden ser muros, guetos y refugios frente a la dimensión sociopolítica de la existencia, que, en unos casos, reducen lo social a lo moral personal (el alcoholismo) y, en otros, sencillamente rechazan la posibilidad del discurso político.

En tercer lugar, el análisis específico de un sector concreto como es el de las organizaciones de voluntariado social en el conjunto de la Comunidad Valenciana permite mostrar la heterogeneidad, diversidad y disparidad intrínsecas del que se conoce como «tercer sector». El tamaño y la estructura de los recursos humanos de las organizaciones o el volumen de recursos económicos que manejan, las diferencian tanto como el tipo de iniciativas que las han constituido, la matriz ideológica, la orientación estructural o el periodo de creación.

18. Ver también Ascoli y Pavolini, 2000, p. 855-856. 
Sin duda, la década de los noventa nos ha sorprendido con una proliferación de múltiples iniciativas, con procesos de institucionalización política (aprobación de leyes, creación de consejos de participación ciudadana) y, en conjunto, con una creciente visibilidad del mundo asociativo, dentro del cual se producen tendencias hacia formas de articulación y vertebración horizontal (foros y plataformas) o vertical (federaciones). Pero sigue predominando la heterogeneidad, la fragmentación y la débil implantación social. Su capacidad para vertebrar la denominada «sociedad civil» es discutible, pese a su proliferación. Y, sin embargo, podemos convenir con Tocqueville (II, 1984: 98) que «los sentimientos y las ideas no se renuevan, el corazón no se engrandece, ni el espíritu humano se desarrolla, sino [es] por la acción recíproca de unos seres humanos con otros». Tocqueville, no obstante, añadía una coda que, a la luz de los datos expuestos, resulta más discutible: «Esto sólo las asociaciones pueden lograrlo».

\section{Anexo. Conglomerados finales de las ONG valencianas}

Centros de los conglomerados finales

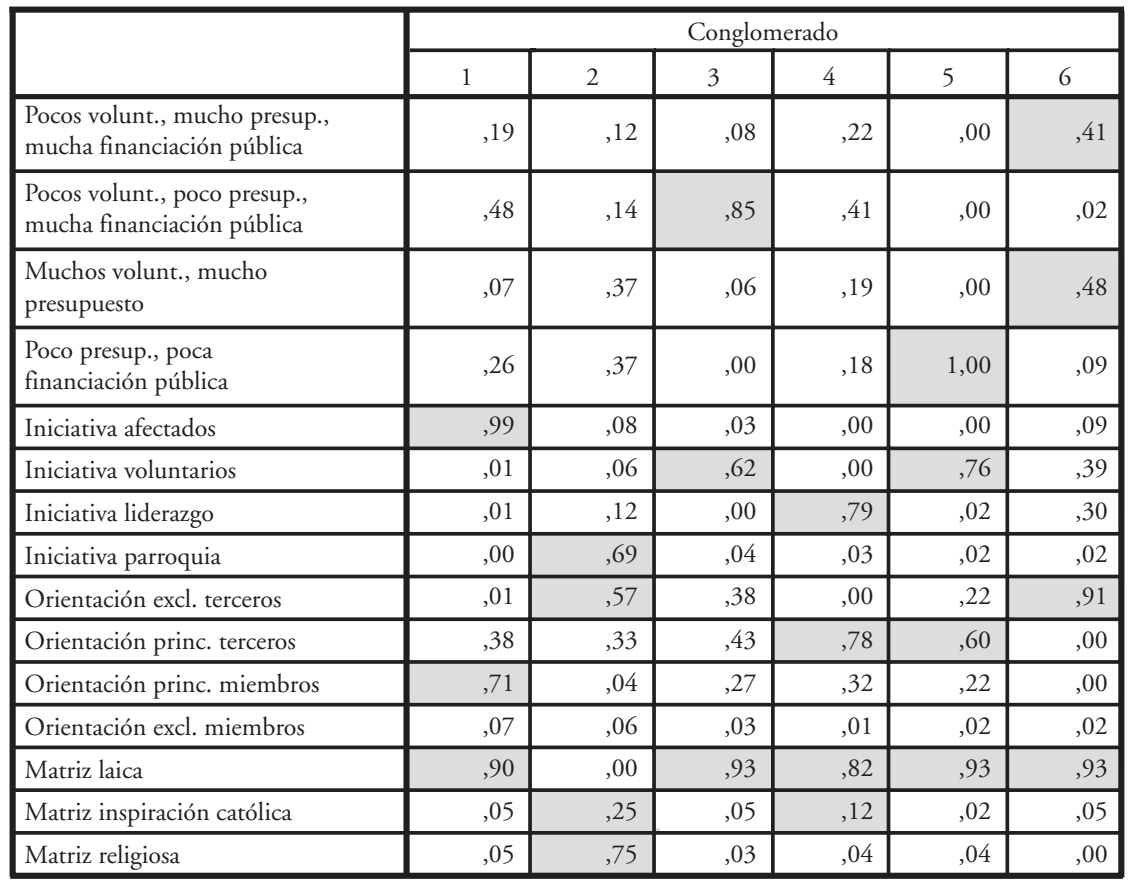

Fuente: ARIÑo, A.; CASTelló, R.; Llopis, R. (2001). La ciudadanía solidaria. 


\section{Bibliografía}

AleXAnder, J.C. (2000). Sociología cultural. Formas de clasificación en las sociedades complejas. Barcelona: Anthropos.

Alonso, L.E. (1999). «La juventud en el tercer sector: redefinición del bienestar, redefinición de la ciudadanía». Revista de Estudios de Juventud, no 45, p. 9-20.

- (2000). Trabajo y posmodernidad: el empleo débil. Madrid: Editorial Fundamentos.

Ambrosini, M. (dir.) (1999). Tra altruismo e profesionalita. Terzo settore e cooperacione in Lombardia. Milán: Franco Angeli.

Aranguren, L.A. (2000). Cartografia del voluntariado. Madrid: PPC.

AriÑo, A.; Albert Rodrigo, M. (2003). L'associacionisme a l'Horta Sud. Un estudi de la societat civil formal en l'àmbit comarcal. Torrent: Fundación para el Desarrollo de l'Horta Sud.

Ariño, A. (dir.); Aliena, R.; Cucó, J.; Perelló, F. (1999). La rosa de las solidaridades. Necesidades sociales y voluntariado en la Comunidad Valenciana. Valencia: Fundació Bancaixa.

AriÑo. A. (dir.); CASTEllo, R.; LlOPIS, R. (2001). La ciudadanía solidaria. El voluntariado y las organizaciones de voluntariado en la Comunidad Valenciana. Valencia: Fundació Bancaixa.

ARIÑO, A.; CuCÓ, J. (2001). «Las organizaciones solidarias. Un análisis de su naturaleza y significado a la luz del caso valenciano». Revista Internacional de Ciencias Sociales, no 29.

AsColi, U.; PAVOLINI, E. (2000). «Las organizaciones del tercer sector en las políticas socio-asistenciales en Europa: comparación de diferentes realidades», en MUÑOZ Machado, S.; García Delgado, J.L.; GonZÁlez SeARA, L. Las estructuras del bienestar en Europa. Madrid: Escuela Libre Editorial, Tecnos, p. 827-858.

BARTHÉlemY, M. (2000). Associations: Un nouvel âge de la participation? París: Presses de Sciences Po. Traducción castellana: Asociaciones: ¿una nueva era de la participación? Valencia: Tirant lo Blanch.

BECK, U. (1991). La sociedad del riesgo. Hacia una nueva modernidad. Barcelona: Paidós.

- (2000). Un nuevo mundo feliz. La precariedad del trabajo en la era de la globalización. Barcelona: Paidós.

Bejar, H. (2000). El corazón de la república. Avatares de la virtud política. Barcelona: Paidós.

- (2001). El mal samaritano. El altruismo en tiempos del escepticismo. Barcelona: Anagrama.

Boissevain, J. (1992). "Introduction», en BoissEvain, J. (ed.). Revitalizng European Rituals. Nueva York: Routledge, p. 1-19.

Bourdieu, P. (1997). Razones prácticas. Barcelona: Anagrama.

CASADO, D. (1992). "Introducción», en CASADO, D. (ed.). Informe sobre las organizaciones voluntarias en España. Barcelona: Editorial Hacer.

- (1999). Imagen y realidad de la acción voluntaria. Barcelona: Editorial Hacer.

CASTEL, R. (1995). La metamorfosis de la cuestión social: una crónica del asalariado. Barcelona: Paidós.

CASTELlS, M. (1997). La era de la información: Economía, sociedad y cultura. Vol. 2: El poder de la identidad. Madrid: Alianza.

CRESPI, F. (1997). Aprender a existir. Nuevos fundamentos de la solidaridad social. Madrid: Alianza. 
Colectivo de Trabajadores Sociales de Salud (1998). Directorio de organizaciones y grupos de ayuda mutua de la ciudad de Valencia. Valencia: IVESP. Conselleria de Sanitat.

Cuco, J. (1992). "Vida asociativa». En García Ferrando, M. (coord.). La sociedad valenciana de los noventa. Valencia: IVEI. Generalitat Valenciana, p. 241-286.

DEP (2001). «Les associations du patrimoine», en Développment culturel, $\mathrm{n}^{\circ}$ 136, p. 1-11.

Diani, M. (1992). "The concept of Social Movement». Sociological Review, vol. 40, no 1 , p. 1-25.

Díez Rodríguez, A. (1999). "Voluntarios, ONG’s y sociedad civil en la reordenación globalizadora». Revista de Estudios de Juventud, no 45, p. 93-102.

DomíngueZ, I.; CERrato, J.; GarcíA, I. (2001). La realidad de las fundaciones en España. Análisis sociológico, psicosocial y económico. Santander: Fundación Marcelino Botín.

DONATI, P. (1993). La cittadinanza societaria. Bolonia: Laterza.

- (1997). «El desarrollo de las Organizaciones del Tercer Sector en el proceso de modernización y más allá». REIS, no 79, p. 113-142.

- (1998). "La crisis del Estado Social y la emergencia del tercer sector: hacia una nueva configuración relacional». Revista del Ministerio de Trabajo y Asuntos Sociales, $\mathrm{n}^{\circ} 5$, p. 15-35.

Eliasoph, N. (1998). Avoiding Politics. How Americans produce apathy in everyday life. Cambridge University Press.

ESPING-ANDERSEN, G. (2000). Fundamentos sociales de las economias postindustriales. Barcelona: Ariel.

FONDAZIONE ITALIANA PER IL VOLONTARIATO (1995). Il volontariato Sociale Italiano. Rapporto di ricerca. Roma.

FukuYama, F. (2000). La Gran Ruptura. Naturaleza humana y reconstrucción del orden social. Barcelona: Ediciones B.

FundaCión TOMILlO (2001). Empleo y trabajo voluntario en las ONG de acción social. Madrid: Ministerio de Trabajo y Asuntos Sociales.

FUNES, M. Jesús (1995). La ilusión solidaria. Las organizaciones altruistas como actores sociales en los regímenes democráticos. Madrid: UNED.

García Delgado, José Luis (2004). Las cuentas de la economía social. El tercer sector en España. Madrid: Civitas.

García Ferrando, M.; ArIÑo, A. (2001). Postmodernización y autonomía. Los valores de los valencianos 2000. Valencia: Tirant lo Blanc.

GARCÍA RocA, J. (2001). «El voluntariado en la sociedad del bienestar». Documentación Social, $\mathrm{n}^{\circ} 122$, p. 15-39.

García RocA, J.; COMES, J. A. (1995). «El voluntariado como recurso social», en FundACIÓ BANCAIXA. El voluntariado. Valencia: Bancaixa, p. 11-148.

Giner, S. (1994). «Lo privado público: altruismo y politeya democrática». Doxa, no 1516, p. 161-177.

- (1995). «El altruismo asociativo en la sociedad civil. A modo de prefacio». En FUNES, M. Jesús. La ilusión solidaria. Las organizaciones altruistas como actores sociales en los regímenes democráticos. Madrid: UNED, p. 13-26.

Giner, S.; SARASA, S. (1997). Buen gobierno y politica social. Barcelona: Ariel.

Godelier, M. (1996). L'enigme du don. París: Fayard.

GorZ, A. (1995). Metamorfosis del trabajo. Madrid: Sistema.

Herrera, M. (1998a). El Tercer Sector en los sistemas de bienestar. Valencia: Tirant lo Blanc. 
- (1998b). "Tercer Sector y sociedad compleja: El debate teórico». Revista del Ministerio de Trabajo y Asuntos Sociales, no 5, p. 49-67.

IBARRA, P.; TEJERINA, B. (1998). «Introducción: hacia unas nuevas formas de acción colectiva", en IBARRA, P.; TEJERINA, B. (eds.). Los movimientos sociales. Transformaciones politicas y cambio cultural. Madrid: Trotta.

Im Hof, U. (1993). La Europa de la Ilustración. Barcelona: Crítica.

IREF (INSTITUTO Di RiCERCHE EDUCATIVE E Formative) (2000). L'impronta cívica. Le forme di partecipazione sociale degli italiani: asociacionismo, voluntariato, donazioni. Edizioni Lavoro.

LE NeT, M. ; WelKIN, J. (1985). Le Volontariat. Aspects sociaux, économiques et politiques en France et dans le monde. París: Notes et Études Documentaires.

MADrID, A. (2001). La institución del voluntariado. Madrid: Trotta.

Marcuello, C.; Bellostas, A.; Marcuello, CH. (coords.) (2001). Economía social y sin ánimo de lucro. Número monográfico de Cuadernos Aragoneses de Economía. Zaragoza.

Mauss, M. (1983). «Essai sur le don. Forme et raison de l'echange dans les sociétés archaïques», en Sociologie et Anthropologie. París: PUF, p. 145-284 (ed. or. 1950).

Medina Tornero, M.E. (1999). Perfil del voluntariado. Murcia: Plataforma para la Promoción del Voluntariado en la Región de Murcia.

MeluCCI, A. (1983). «Mouvements sociaux, mouvements post-politiques». Revue International d'Action Communitaire, no 10.

Montagut, T. (2000). Política social. Una introducción. Barcelona: Ariel.

MonTORO, R. (1997). "La reforma del Estado de bienestar: derechos, deberes e igualdad de oportunidades». Revista Española de Investigaciones Sociológicas, no 79, p. 9-41.

Murillo, S. (1996). El mito de la vida privada. De la entrega al tiempo propio. Madrid: Siglo XXI.

Pérez DíAz, V.; Pérez Novo, J. (2003). El tercer sector social en España. Madrid: Ministerio de Trabajo y Asuntos Sociales.

Plataforma Para la Promoción del Voluntariado en EsPaña (1997). Las organizaciones de voluntariado en España. Madrid: Ministerio de Trabajo y Asuntos Sociales. RifKIN, J. (1996). El fin del trabajo. Barcelona: Paidós.

Rodríguez Cabrero, G. (1996). Participación social de las personas mayores. Madrid: Ministerio de Trabajo y Asuntos Sociales.

- (1999). «Políticas de empleo y Tercer Sector». Revista de Estudios de Juventud, no 45, p. 21-32.

- (coord.) (2003). Las entidades voluntarias de acción social en España. Informe General. Madrid: Fundación Foessa.

Rodríguez Cabrero, G.; Codorniu, M. (1996). Las entidades voluntarias en España. Institucionalización, estructura económica y desarrollo asociativo. Madrid: Ministerio de Asuntos Sociales.

Rodríguez Villasante, T. (1997). «Del Tercer Sector al Tercer Sistema. Los nuevos valores que estamos construyendo los ciudadanos», en Sobre vivir y transformar la ciudad. Valencia: Fundación Hugo Zárate.

Ruiz de Olabuénaga, J.I. (1994). «Ocio y estilo de vida», en JuÁreZ, M. (dir.). $V$ Informe sobre la situación social en España. Sociedad para todos en el año 2000. Madrid: Fundación FOESSA, p. 1.883-2.040.

- (2000). El sector no lucrativo en España. Madrid: Fundación BBV.

- (2001). "El sector no lucrativo. Retos y riesgos, fortalezas y debilidades». Cuadernos Aragoneses de Economía, 2a época, vol. 11, no 2, p. 265-282. 
SajaRdO, A. (1996). Análisis económico del sector no lucrativo. Valencia: Tirant lo Blanch. - (1998). El sector no lucrativo en el ámbito de los servicios sociales de la Comunidad Valenciana. Valencia: Ciriec España.

Salamon, L.; ANHEIER, H.K. (1992a). «In search of the non profit sector. I: The question of definitions». Voluntas, no 3/2, p. 125-152.

- (1992b). «In search of the non profit sector. I: The problem of classification». Voluntas, no 3/3, p. 266-309.

- (1996). The Emerging Nonprofit sector: An Overview. Manchester: Manchester University Press.

SEBASTIÁn, L. de (1997). La solidaridad. Barcelona: Ariel.

SUBIRATS, J. (ed.) (1999). ¿Existe sociedad civil en España? Madrid: Fundación Encuentro. TocQueville, Alexis de (1984). La democracia en América, I y II. Madrid: Sarpe.

VAN TIL, J. (1988). Maping the Third Sector. Voluntarism in a changing social economy. The Foundation Center.

VINYES, R. (1996). "Aproximación histórica a las asociaciones de carácter no lucrativo en el ámbito de los servicios sociales», en RODRíGUez CABRERO, G.; CODORNIU, M. (1996). Las entidades voluntarias en España. Institucionalización, estructura económica y desarrollo asociativo. Madrid: Ministerio de Asuntos Sociales.

Volmed Project (1999). Organised Voluntary Services in the Countries of Mediterranea Europe: Greece, Italy, Portugal, Spain. Fondazione Italiana per il Voluntariato, material fotocopiado.

WiLSON, John (2000). «Volunteering». Annual Review of Sociology, no 26, p. 215-240. Wuthnow, R. (1991): Actos de compasión. Cuidar de los demás y ayudarse uno mismo. Madrid: Alianza Editorial. 